\title{
BIG METALLIC FOREIGN BODY IN THE ENDOCERVIX - A CASE REPORT
}

Mainak Sen ${ }^{1}$

\section{HOW TO CITE THIS ARTICLE:}

Mainak Sen. "Big Metallic Foreign Body in the Endocervix - A Case Report". Journal of Evolution of Medical and Dental Sciences 2014; Vol. 3, Issue 04, January 27; Page: 820-823, DOI: 10.14260/jemds/2014/1909

ABSTRACT: Foreign objects in the female genital tract neglected for a long period of time may lead to many clinical problems, most commonly recurrent vaginal discharge. The diagnosis requires detailed history and physical examination of the genital tract. Though very uncommon big metallic foreign body may be encountered in the endocervix. We present a case of a 22-year-old female who presented with vaginal discharge and failure of evacuation of retained products of conception to emphasize the importance of establishing a diagnosis of foreign body in the endocervix in suspected cases.

KEYWORDS: Foreign body, Endocervix.

INTRODUCTION: Vaginal discharge is a common gynecological complaint with many different etiologies. One of the causes is the presence of a foreign body in the lower genital tract. ${ }^{1} \mathrm{~A}$ foreign body located in the genital tract can lead to various clinical problems including purulent vaginal discharge, scarring in the vagina, fistula formation, recurrent urinary tract infections and infertility. ${ }^{2-}$ 5

Foreign bodies are found in the female genital tract which may be due to accidental or iatrogenic insertion. Foreign bodies are sometimes introduced higher up in the genital tract for the purpose of termination of unwanted pregnancies. However presence of a big foreign body impacted in the endocervix and remaining asymptomatic and silent is a remote possibility.

CASE REPORT: A 22 years old female para 1+1, with a history of caesarean section was referred to the hospital with a foul smelling vaginal discharge and high fever. No documents of her previous pregnancy and its management were available. She had a history of intake of some abortifacient for medical termination of pregnancy about three weeks back which failed following which she went to a doctor for surgical evacuation which was also abandoned as instruments could not be negotiated through the external os.

History revealed insertion of foreign body about 12 years back in the lower genital tract before she was sexually active.

Examination revealed gross pallor and high temperature. She had no other medical or surgical illnesses. On physical examination, the external genitalia looked normal. On speculum examination, the vaginal walls were normal. Speculum examination revealed pus trickling through the external os which was closed. Cervix was flushed with the vault and deviated to the right. Bimanually the cervix was bulky, hard and there was fullness in the right fornix, contour of the uterus could not be properly delineated.

A sound was very gently negotiated through the external os but a metallic obstruction was felt above $1 \mathrm{~cm}$ the external os. 


\section{Investigations:}

1. Straight $X$ ray Pelvis: large metallic foreign body was revealed. (Figure-1).

2. USG of Pelvis: Incomplete abortion.

Elongated cervix with a high echogenic lesion in the mid-cervical region (Figure 2).

3. Routine haematological examination revealed anemia and signs of infection.

Management: Patient was stabilized with blood transfusion and antibiotics. She was subsequently booked for examination under anesthesia to properly evaluate the pathology. An examination under anesthesia revealed a small sinus tract in the vagina, which was thought to be a narrowed cervix. Following Foley's catheterization cervix was grasped and stitches were given at 3'o clock and 9'o clock position. Careful incision was given at 5'o clock position and cervical canal was widened up by extending the incision superiorly. The foreign body was grasped by Allis' tissue forceps and gently pulled down. A metallic cylindrical foreign body of $3 \mathrm{cms}$ x $2 \mathrm{cms}$ (figure-3) was taken out through the cervix by cutting the rest of the cervical fibres. Cervix was repaired carefully and a Foleys' catheter with its inflated bulb was kept inside the uterine cavity to maintain the patency of the cervical canal.

Post-operative period was uneventful.

DISCUSSION: A foreign object in the female genital tract is one of the causes of vaginal discharge, particularly in pre-pubertal females. Clinicians should have high clinical suspicion, if the symptoms do not resolve after empirical treatment with antibiotics. Stricker et $\mathrm{al}^{3}$ reviewed records of 35 girls with the diagnosis of a vaginal foreign body. A carefully obtained medical history and physical examination could easily suggest the diagnosis. The most common symptoms were vaginal bleeding, and bloodstained or foul-smelling vaginal discharge. Management is the removal of the foreign object, and simple irrigation with an antiseptic solution. No additional treatments were necessary. ${ }^{5}$ The clinical course should alert the health care provider to the presence of a foreign body.

Neulander et $\mathrm{al}^{6}$ reported that recurrent urinary tract infections could be the presenting symptom for the presence of a vaginal foreign body in children. High level of suspicion and strict basic diagnostic protocols were the most important steps for a timely diagnosis.

Smith et al7 reported that in children with foreign bodies as a cause of persistent vaginal discharge, vaginal irrigation was feasible. However, irrigation should be delayed until the foreign body was seen prior to the procedure. ${ }^{7}$

CONCLUSION: The suspicion of a foreign body in the female genital tract may arise after a medical history and physical examination. Resistance to empirical antibiotic therapy should lead the physicians to more extensive investigation and management options. A detailed discussion of the situation with the family may aid in obtaining the consent. The family and the patient should be informed regarding the possible complications, including recurrent vaginal discharge, fistula formation, and infertility. 


\section{REFERENCES:}

1. Nanda S, Singhal SR, Marya A. Foreign bodies retained in the vagina: a case report. J Reprod Med 2006; 51: 329-330.

2. Simon DA, Berry S, Brannian J, Hansen K. Recurrent, purulent vaginal discharge associated with longstanding presence of a foreign body and vaginal stenosis. J Pediatr Adolesc Gynecol 2003; 16: 361-363.

3. Stricker T, Navratil F, Sennhauser FH. Vaginal foreign bodies. J Paediatr Child Health 2004; 40: 205-207.

4. Ahmad M. Intravaginal vibrator of long duration. Eur J Emerg Med 2002; 9: 61-62.

5. Stricker T, Navratil F, Sennhauser FH. Vaginal foreign bodies. J Paediatr Child Health 2004; 40: 205-207.

6. Neulander EZ, Tiktinsky A, Romanowsky I, Kaneti J. Urinary tract infection as a single presenting sign of multiple vaginal foreign bodies: case report and review of the literature. J Pediatr Adolesc Gynecol 2010; 23: 31-33.

7. Smith YR, Berman DR, Quint EH. Premenarchal vaginal discharge: findings of procedures to rule out foreign bodies. J Pediatr Adolesc Gynecol 2002; 15: 227-230.

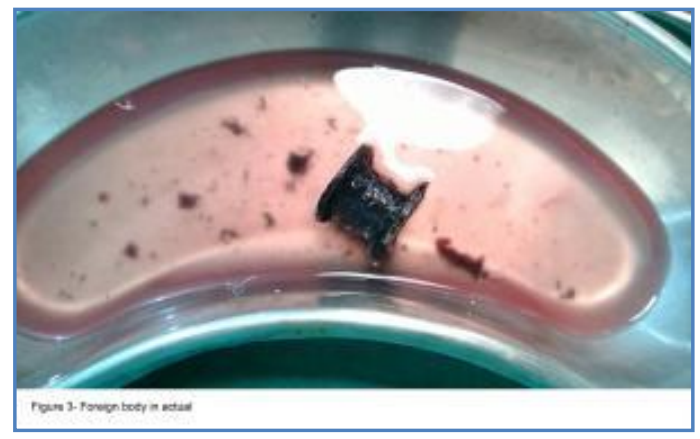

Foreign Body

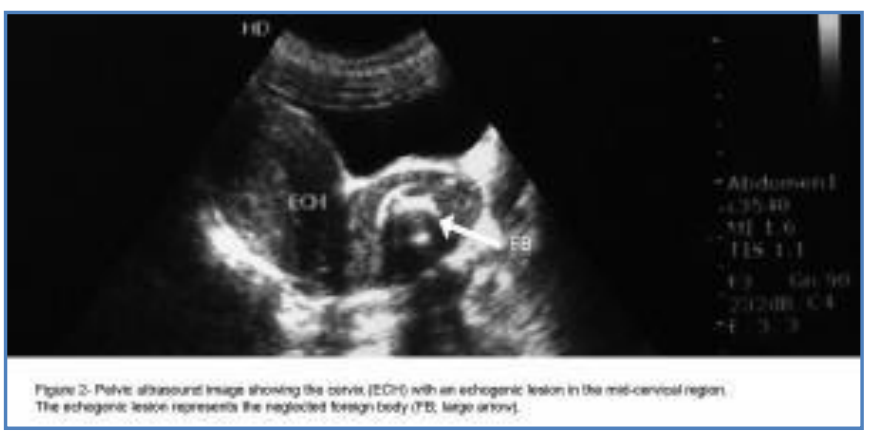

USG pelvis 


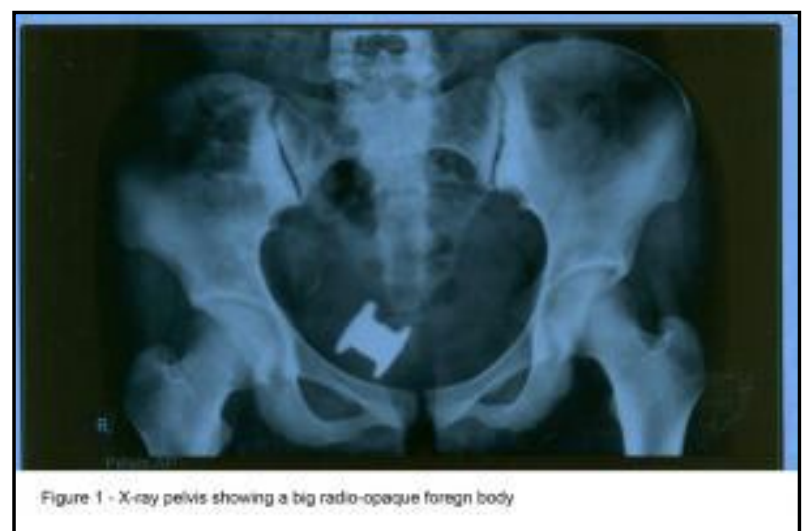

X-Ray pelvis

\section{AUTHORS:}

1. Mainak Sen

\section{PARTICULARS OF CONTRIBUTORS:}

1. RMO Cum Clinical Tutor, Department of Obstetrics and Gynaecology, Malda Medical College and Hospital, West Bengal.

\section{NAME ADDRESS EMAIL ID OF THE}

\section{CORRESPONDING AUTHOR:}

Dr. Mainak Sen,

Neelachal Abasan Co-Operative Society, 98, Rajdanga Gold Park,

Flat - Purba B4, Kolkata-107.

E-mail: mainak_sen1977@yahoo.co.in

Date of Submission: 05/01/2014. Date of Peer Review: 06/01/2014. Date of Acceptance: 10/01/2014.

Date of Publishing: 21/01/2014. 